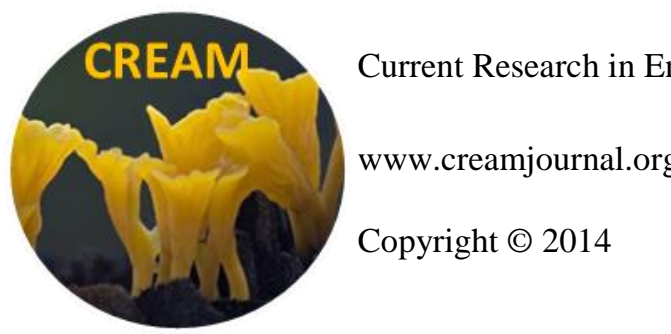

\title{
A new species of Corynespora from Sonebhadra forest of Uttar Pradesh, India
}

\author{
Singh $A^{1}$, Kumar $S^{2}$, Singh $\mathbf{R}^{3}$ and Dubey $\mathrm{NK}^{1}$ \\ ${ }^{1}$ Center of Advanced Study in Botany, Banaras Hindu University, Varanasi -221 005 (U.P.), India. \\ ${ }^{2}$ Birbal Sahni Institute of Palaeobotany, 53, University Road, Lucknow-226 007(U.P.), India. \\ ${ }^{\mathbf{3}}$ Department of Botany, H.S. Gaur University, Sagar-470003 (M.P.), India.
}

Singh A, Kumar S, Singh R, Dubey NK 2014 - A new species of Corynespora from Sonebhadra forest of Uttar Pradesh, India. Current Research in Environmental \& Applied Mycology 4(2), 149151, Doi 10.5943/cream/4/2/1

\begin{abstract}
Corynespora moracina is described and illustrated on Ficus hispida (Moraceae) collected from forest flora of Sonebhadra, Uttar Pradesh, India.
\end{abstract}

Key words - Fungal diversity - foliar disease - morphotaxonomy - Sonebhadra forest Corynespora - new species

\section{Introduction}

The genus Corynespora caused foliar disease on angiosperms especially in tropical and subtropical regions.

During our survey of the forest region of Sonebhadra of District Mirzapur, Uttar Pradesh, India many collections showing foliar diseases have been collected. Upon critical morphological examination and comparison with closely related taxa Corynespora moracina on Ficus hispida (Moraceae) appeared as a novel species and is described here.

\section{Materials \& Methods}

Surface scrapping and free hand cut sections were made with razor blade of infected leaf samples, collected from forest flora of Sonebhadra of district Mirzapur, Uttar Pradesh, $\left(24^{\circ} 42^{\prime} \mathrm{N}\right.$ to $25^{\circ} 3^{\prime} 55^{\prime} \mathrm{N}$ and $83^{\circ} 3^{\prime} 24^{\prime \prime} \mathrm{E}$ to $83^{\circ} 22^{\prime} 55^{\prime \prime} \mathrm{E}$ ). Sections were taken through infection spots and mounted in lactophenol cotton blue for microscopic examination. Detailed observations of morphological characters were carried out using an Olympus CX-31 light microscope (1000x). Measurements were made of 20 conidia and conidiophores. Line drawings were prepared by camera lucida at a magnification of $1000 \times$. Type specimen has been deposited in Herbarium Cryptogamiae Indiae Orientalis (HCIO), Indian Agriculture Research Institute (IARI), New Delhi and an isotype retained in the departmental herbarium (Banaras Hindu University). Descriptions and nomenclatural details were deposited in MycoBank (www.Mycobank.org). 


\section{Results}

\section{Taxonomy}

Corynespora moracina Archana Singh, Sham. Kumar, R. Singh \& Dubey sp. nov.

Fig. 1

MycoBank MB 801328

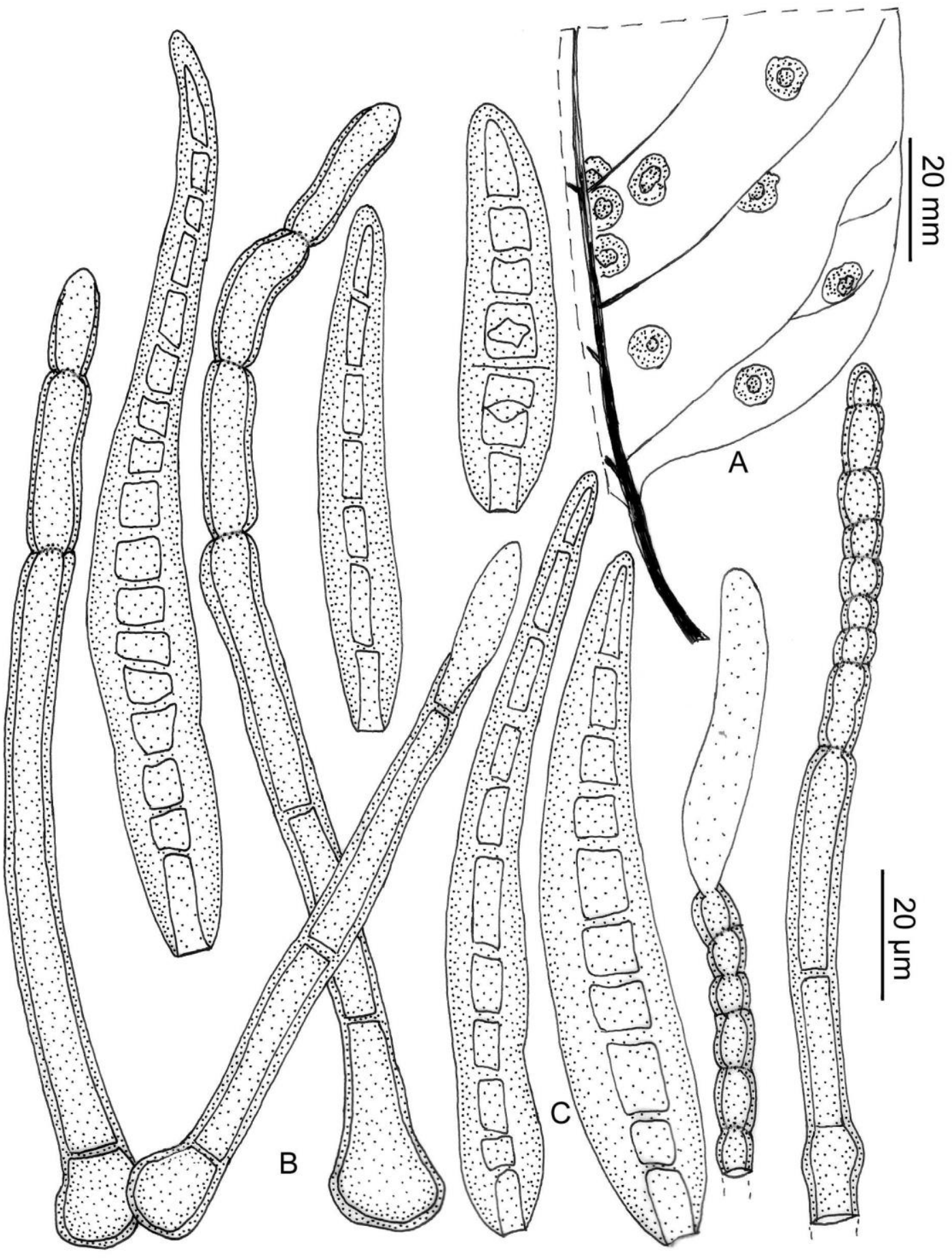

Fig. 1 - Corynespora moracina. 1 Infection spots. 2 Conidiophores. 3 Conidia. Bars $\mathrm{a}=20 \mathrm{~mm}, \mathrm{~b}=20$ $\mu \mathrm{m}$. 
Etymology - Moracina, refers to the host family Moraceae.

Infection spots amphigenous, circular to sub circular, spreading on entire leaf surface, greyish brown to dark brown, up to $7 \mathrm{~mm}$ in diam. Colonies hyphophyllous, effuse. Mycelium internal, composed of branched, septate, thin-walled, smooth, subhyaline to olivaceous hyphae. Stroma absent. Conidiophores macronematous, mononematous, arising singly from hyphae, erect, straight to flexuous, smooth, thick- walled, cylindrical, unbranched or rarely branched, 2 to 7 septate, 1-8 successive, cylindrical terminal proliferations, dark brown, 135-412 × 7-9 $\mu \mathrm{m}$. Conidiogenous cells integrated, terminal to intercalary, monotretic, smooth, cylindrical, scars unthickened, swollen towards apex. Conidia acrogenous, solitary, simple, dry, thin-walled, smooth, straight to slightly curved, obclavato-cylindrical, 5-16 distoseptate, apex obtuse to rounded, base obclavate, light olivaceous-brown, hilum unthickened, 27-163 × 12-20 $\mu \mathrm{m}$.

Type: On living leaves of Ficus hispida L. (Moraceae), Sonebhadra, (U.P.), India, Nov. 2009, coll., Archana Singh HCIO 50141 (holotype), BHU herb No. 9054 (isotype).

Literature survey revealed that three species of Corynespora have been described on host genus Ficus viz. C. fici-altissimae Zhang \& Xu (2005), C. fici-benjaminae Zang, Fu \& Zhang (2009) and C. ficigena Singh et al. (2012). Hence the morphological comparison of present species is done with these three closely related taxa for its novelty.

From morphological comparison it is clear that conidiophores are unbranched in previously described closely related species while branched in $C$. moracina. The conidiophores are comparatively longer $(135-412 \times 6-8 \mu \mathrm{m})$ in $C$. moracina than those of $C$. fici-altissimae $(30-65 \times$ 5-6 $\mu \mathrm{m})$ and shorter than $C$. fici-benjaminae $(152-467 \times 5.5-11 \mu \mathrm{m})$. The conidiophores of present species have fewer (1-8) successive proliferations as compared to earlier described related species (up to 3). The conidia in $C$. moracina are $(27-163 \times 12-20 \mu \mathrm{m})$ and average distoseptate (5-16) than $C$. fici-altissimae $(55-85 \times 9-12 \mu \mathrm{m}, 7-13$ distoseptate $)$ and $C$. fici-benjaminae $(51.5-71 \times 8-$ $11 \mu \mathrm{m}, 5-10$ distoseptate).

The dimension of conidiophores and conidia of both ( $C$. moracina and C. ficigena) are similar but $C$. moracina is distinctly different due to presence of unbranched conidiophores as compared to $C$. ficigena having branched conidiophores. Therefore, the present species merits recognition as a new taxon.

\section{Acknowledgements}

Authors are grateful to the Head, Department of Botany, Banaras Hindu University (BHU), Varanasi, Uttar Pradesh, India for providing library and laboratory facilities. Author's thanks are also due to the Curator, HCIO, IARI, New Delhi for depositing the holotype specimens and providing accession numbers thereof. Thanks are also due to Department of Science and Technology, New Delhi for assistant to first author. Authors are very much obliged to Prof. McKenzie for useful suggestions and comment after going through review of the manuscript.

\section{References}

Singh A, Kumar S, Singh R, Dubey NK. 2012 - A new species of Corynespora causing foliar disease on Ficus religiosa from forest of Sonebhadra, Uttar Pradesh, India. Mycosphere 3(5), 890-892. Doi 10.5943 /mycosphere/3/6/2

Zhang Xiu-Guo, Xu Jun-Jie. 2005 - Taxonomic studies of Corynespora from Guangxi, China. Mycotaxon 92, 431-436.

Zhang K, Fu Hong-Bo, Zhang Xiu-Guo. 2009 - Taxonomic studies of Corynespora from Hainan, China. Mycotaxon 109, 85-93. 